\title{
Chapter Green Nanotechnology: Development of Nanomaterials for Environmental and Energy Applications
}

\author{
Rachel Fagan \\ Technological University Dublin, rachel.fagan@mydit.ie \\ Changseok Han \\ University of Cincinnati \\ Joel Andersen \\ University of Cincinnati
}

See next page for additional authors

Follow this and additional works at: https://arrow.tudublin.ie/engschivbk

Part of the Civil Engineering Commons

\section{Recommended Citation}

Fagan, R. (2013) Chapter Green Nanotechnology: Development of Nanomaterials for Environmental and Energy Applications, in Shamim, N., et al., In Sustainable Nanotechnology and the Environment: Advances and Achievements. Washington, DC, American Chemical Society: 2013.

This Book Chapter is brought to you for free and open access by the School of Civil and Structural Engineering at ARROW@TU Dublin. It has been accepted for inclusion in Books/Book Chapters by an authorized administrator of ARROW@TU Dublin. For more information, please contact arrow.admin@tudublin.ie, aisling.coyne@tudublin.ie,gerard.connolly@tudublin.ie. 


\section{Authors}

Rachel Fagan, Changseok Han, Joel Andersen, Suresh Pillai, Polycarpos Falaras, Anthony Byrne, Patrick S.M. Dunlop, Hyeok Choi, Wenjun Jiang, Kevin O'Shea, and Dionysios D. Dionysiou 
Chapter 12

\title{
Chapter Green Nanotechnology: Development of Nanomaterials for Environmental and Energy Applications
}

\author{
Changseok Han, ${ }^{1}$ Joel Andersen, ${ }^{1}$ Suresh C. Pillai, ${ }^{2}$ \\ Rachel Fagan, ${ }^{2}$ Polycarpos Falaras, ${ }^{3}$ J. Anthony Byrne, ${ }^{4}$ \\ Patrick S. M. Dunlop, ${ }^{4}$ Hyeok Choi, ${ }^{5}$ Wenjun Jiang, ${ }^{6}$ \\ Kevin O'Shea, ${ }^{6}$ and Dionysios D. Dionysiou ${ }^{*}, 1,7$
}
1 Environmental Engineering and Science Program, University of Cincinnati, Cincinnati, Ohio 45221-0012, U.S.A.
${ }^{2}$ Centre for Research in Engineering Surface Technology (CREST) FOCAS Institute, Dublin Institute of Technology, Kevin St., Dublin 8, Ireland 3Division of Physical Chemistry, Institute of Advanced Materials, Physicochemical Processes, Nanotechnology and Microsystems (IAMPPNM), National Center for Scientific Research "Demokritos", 15310 Aghia Parakevi Attikis, Athens, Greece
${ }^{4}$ Nanotechnology and Integrated BioEngineering Centre, School of Engineering, University of Ulster, Northern Ireland, BT37 0QB, United Kingdom
5Department of Civil Engineering, The University of Texas at Arlington, Arlington, Texas 76019-0308, U.S.A.
6Department of Chemistry and Biochemistry, Florida International
University, University Park, Miami, Florida 33199, U.S.A.
${ }^{7}$ Nireas-International Water Research Centre, University of Cyprus, 20537 Nicosia, Cyprus
"E-mail: dionysios.d.dionysiou@uc.edu

This book chapter discusses the syntheses of various nanomaterials, for green nanotechnology applications in detail. Special attention is given to the development of emerging areas, such as environmental as well as energy materials. Various approaches for preparing nanostructured photocatalysts, such as titanium dioxide, zinc oxide, iron oxide, and metal sulfides, different conventional methods and novel methods, including 
sol-gel methods, hydrothermal methods, microwave-assisted methods and sonochemical methods are introduced. The use of nanomaterials as photocatalysts, supporting materials for solar cells, and disinfectants is reported for environmental remediation and energy applications. Advanced applications of nanomaterials for water detoxification, air purification, and the inactivation of pathogenic microorganisms in water as well as dye-sensitized solar cells is also discussed. The enhancement of selectivity of photocatalysis, especially $\mathrm{TiO}_{2}$ systems, for the destruction of target contaminants in water is comprehensively presented. Finally, the role of reactive oxygen species (ROS), such as hydroxyl radical $(\cdot \mathrm{OH})$, superoxide anion radical $\left(\mathrm{O}_{2}{ }^{--}\right)$, singlet oxygen $\left({ }^{1} \mathrm{O}_{2}\right)$ and hydrogen peroxide $\left(\mathrm{H}_{2} \mathrm{O}_{2}\right)$, in semiconductor photocatalysis is introduced and various experimental techniques to detect ROS are also discussed.

\section{Introduction}

Environmental pollution due to anthropogenic activities has become a serious problem for developing and developed countries in the world. Pollution has affected various plants and animals in the ecosystem, as well as humans around the world. Therefore, there is a need for techniques to remediate the polluted environment. Photocatalytic oxidation using semiconductors as catalysts has become an attractive candidate as a green technology for environmental applications, such as water cleaning (1), air purification (2), and soil remediation (3) ever since Fujishima and Honda (4) discovered the photoinduced water cleavage of $\mathrm{TiO}_{2}$. Photocatalysis has been employed to degrade toxic organic compounds, dyes, pesticides, volatile organic compounds, harmful gases, and bacteria $(3,5-9)$ in different media. Therefore, photocatalysis has been intensively studied over the last two decades as a clean and green process to decompose pollutants in the environment. Recently, nanomaterials have received significant attention for environmental and energy applications because their size, shape, crystallinity, and surface can provide unique physical and chemical properties, such as high surface area, well-defined structure, high dispersibility, and high reactivity $(10,11)$.

Intensive research efforts have been focused on the development of novel nanostructured materials. Many nanostructured materials, such as titanium dioxide, zinc oxide, iron oxide, metal sulfide, have been synthesized with different techniques, including sol-gel methods, hydrothermal methods, and chemical deposition methods (12-15). Green nanotechnology has the potential to help us to obtain desirable materials with low toxicity and cost, high chemical and thermal stability, and high degradation activity for environmental remediation $(12,13)$. This chapter will discuss the syntheses of various nanomaterials and their environmental and energy applications. In addition, selectivity issues of $\mathrm{TiO}_{2}$ photocatalysis and reactive oxygen species during photocatalysis will be discussed. 


\section{Preparation of Nanomaterials for the Green Nanotechnology}

There are many approaches to creating nanostructured materials. With respect to materials such as titanium dioxide, zinc oxide, and iron oxide, conventional approaches include sol-gel (16), chemical vapor deposition (CVD) (17), pyrolysis (18) and hydrothermal treatment $(19,20)$. The sol-gel approach will be emphasized in detail, but brief introductions to the other conventional methods will be provided, and new developments will be addressed later.

All the synthesis methods have the end goal of creating a high-purity product. To reach this end, however, each method exploits different aspects of chemistry. For example, the CVD method for creating ceramics involves the transport of gaseous metal halides with gaseous oxygen, carbon, nitrogen, or boron depending upon the desired product $(21,22)$. This transport is done above a heated substrate upon which the solid material can deposit. One alternative to CVD is spray pyrolysis. In spray pyrolysis, solutions containing precursors (e.g., $\mathrm{TiCl}_{4}$ for titanium or $\mathrm{NH}_{4} \mathrm{~F}$ for nitrogen/fluorine) are atomized by a nebulizer. The droplets undergo pyrolysis while passing through a high-temperature container. Collection of the generated powders can be done on a ceramic filter at the container's terminal. (23). Another high-temperature approach is called hydrothermal treatment. In hydrothermal treatment, synthesis of a new material is performed under elevated temperature and pressure conditions in a sealed vessel (24). In this case, formation behavior occurs according to a liquid nucleation model. One final synthesis approach, the sol-gel approach, allows for great customizability in the final titania product.

The sol-gel process was thoroughly reviewed by Hench and West in 1990 (25). Two major benefits of the sol-gel process include increased purity and homogeneity in comparison to conventional synthesis methods for ceramics. Hench and West describe a "sol" as a liquid containing dispersed colloids; however, it is pertinent to include nanoparticles in addition to colloids. "Gel" implies a rigid network of interconnected pores (size $<1 \mu \mathrm{m}$ ). The sol-gel is approach is thus a wet-chemistry based approach. In preparing the sol-gel, precursors are selected and supplied to control the various desired product parameters (surface area, roughness, dopants, etc.). The final solid product can be obtained by subsequently calcining in a furnace. During this calcination process, volatile species in the sol-gel are removed, leaving the desired product in good purity.

\section{1. $\mathrm{TiO}_{2}$ Photocatalyst}

As described above, various methods are capable of synthesizing various ceramic products. One commonly synthesized ceramic product of interest is titanium dioxide. This semiconductor is a photocatalyst with a band gap of $3.2 \mathrm{eV}(4,26)$. Examples of applications include air and water remediation, anti-fogging glass, cancer treatment, and solar cells $(27,28)$. Effectiveness of a given application may be optimized by the synthesis method chosen. Examples of parameters of titanium dioxide that can be optimized for various applications include, but are not limited to: crystal phase, band gap, surface area, porosity, 
roughness, and particle-size distribution. The sol-gel approach has enough flexibility to allow for many parameters to be altered simultaneously.

To begin, photocatalytic effectiveness is strongly correlated with adsorptive capabilities of the catalyst for a given contaminant. The adsorptive efficacy of a surface is a function of film properties such as surface area, porosity, and roughness, amongst other factors. $\mathrm{TiO}_{2}$ surface area may be increased during the sol-gel process by incorporating a surfactant $(29,30)$, which can simultaneously tailor pore size and porosity to meet various needs. This tailoring occurs at a sufficient surfactant concentration, the critical micelle concentration (CMC). At the $\mathrm{CMC}$, the surfactant will form micelles in solution, which act as a scaffolding of sorts around which the titania framework forms. The framework stays in place during and after calcination even as the surfactant is removed by heat. The inclusion of a surfactant also offers an opportunity for doping.

When a photocatalyst is doped with impurities, the effective band gap can be decreased. As mentioned earlier, conventional $\mathrm{TiO}_{2}$ has a band gap of $3.2 \mathrm{eV}$. This requires an incident photon whose energy corresponds to ultraviolet light. UV light only accounts about $5 \%$ of the solar spectrum; therefore, it is beneficial to decrease the effective band gap and extend the activity to a large portion of the solar spectrum (30). Pelaez et al. used a nonionic fluorosurfactant (Zonyl FS-300), which not only controlled adsorptive qualities, but also lent fluorine atoms to the final structure (30). In this study, a non-surfactant doping method was included as well, ethylenediamine, which acted as a nitrogen source. The final product was $\mathrm{N}$, F-codoped titania, with a band gap of $2.75 \mathrm{eV}$. Other non-metal dopants have been employed such as sulfur (31) and carbon (32). Metallic dopants, both transition metals and rare earth metals, have been used with success as well, including Fe (33), Cr, Mn, and Co (34), and rare earth metals (La, Ce, Er, Pr, Gd, Nd, Sm) (35). Figure 1 shows the effect of doping on the photoexcitation mechanism of $\mathrm{TiO}_{2}$. An additional factor that has influence on band gap and activity is the crystal phase.

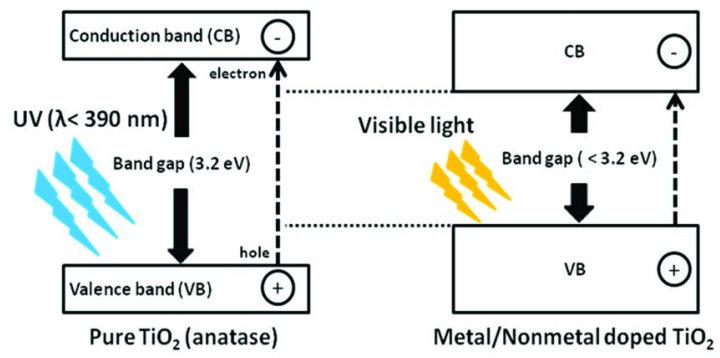

Figure 1. Schematic of photoexcitation mechanism of $\mathrm{TiO}_{2}$.

Titania has several possible crystal phases: anatase, rutile, and brookite. If a titania sample is not one of the above phases, it is amorphous. Although rutile titania has a smaller band gap $(3.0 \mathrm{eV})$, anatase titania offers higher adsorptive capability for organic compounds and also has lower recombination rates (36). Therefore, anatase is commonly considered the preferred phase. Crystal phase can be altered in a calcination step. Rutile is generally the most common phase 
at high temperatures $(\mathrm{T}>\sim 1000 \mathrm{~K})$, and at lower temperatures, crystallinity will depend strongly on not only temperature, but also particle size (37).

Particle size in prepared samples generally is not a well-defined value, but rather it is a distribution of values. However, work to develop relatively monodisperse titania has been successful through the addition of salts and polymers (38). Han et al. (39) employed a simple approach that involved altering the concentration of calcium chloride in solution. With this method, particle size was inversely proportional to calcium chloride concentration. Such a method allows for nanotoxicology researchers to do toxicity studies on novel nanoparticles while controlling for size effects.

Beyond particle size, band gap, crystal phase, surface area, and similar structural properties, research has also explored the possibility of decorating titania. Decorating, not be confused with doping, involves the addition of a metal, such as silver (40), gold (41), copper (42), and platinum (43) to the external surface of the titania. Using silver as an example, Srisitthiratkul et al. (40) decorated particles by dispersing titania particles in solution $\left(1 \mathrm{~g} \mathrm{~L}^{-1}\right)$ with sonication for 10 minutes and subsequently adding $0.1 \mathrm{~g} \mathrm{~L}^{-1}$ silver nitrate with stirring for another 10 minutes. The benefit of decorating with silver comes from silver's antimicrobial activity. They observed antimicrobial behavior by Ag-decorated $\mathrm{TiO}_{2}$ in the absence of light, whereas control $\mathrm{TiO}_{2}$ demonstrated no such behavior.

\subsection{Metal Oxide and Metal Sulfide Photocatalysts}

Other metal oxide and metal sulfide nanomaterials, such as $\mathrm{ZnO}, \mathrm{Fe}_{2} \mathrm{O}_{3}, \mathrm{CdS}$, and $\mathrm{ZnS}$, have been employed as photocatalysts for the degradation of organic contaminants $(12,44-46)$. To synthesize those nanomaterials, various methods, such as chemical bath deposition, hydrothermal treatment, ball milling, and sol-gel method, has been employed. A brief synopsis of several synthesis methods was provided in the previous section 1 .

Zinc oxide (direct band gap of $3.37 \mathrm{eV}$ ) has been intensively studied over the past few decades due to its broad applications in solar cells, sensors, light-emitting diodes, and photocatalyst (44, 47-49). $\mathrm{ZnO}$ nanoparticles were synthesized by a ball milling method using a conventional ball mill with chemical reactions, which were activated mechanically during the grinding. The average particle size of synthesized $\mathrm{ZnO}$ nanoparticles ranged from 20 to $30 \mathrm{~nm}$ (50). Ao et al. (51) and Shen et al. (52) reported that particle size depended on the milling time and the temperature of heat treatment. The particle size decreased with increasing the milling time while it increased at higher heat treatment temperature. In order to improve the physical and chemical properties of $\mathrm{ZnO}$ and enhance the photocatalytic activity of $\mathrm{ZnO}$, much research effort has been focused on the control of materials' morphology. Various nanostructured $\mathrm{ZnO}$ nanomaterials, such as nanowire, nanorods, nanotubes, and nanodisks, have been synthesized (44, 53-56). $\mathrm{ZnO}$ nanowires for photocatalytic application were synthesized by a modified carbothermal reduction method at $1150{ }^{\circ} \mathrm{C}(44)$. A large amount of well-crystallized nanowires with an average diameter of $33 \mathrm{~nm}$ were obtained. Eighty percent of source $\mathrm{ZnO}$ powders converted to $\mathrm{ZnO}$ nanowires within 5 
min. In addition to nanowires, the synthesis of $\mathrm{ZnO}$ nanotubes, nanorods, and nanodisks has been reported in order to enhance the photocatalytic reactivity. $\mathrm{Lu}$ et al. (53) obtained $\mathrm{ZnO}$ nanotubes by thermal oxidation of $\mathrm{Zn}$ nanowires. In the furnace chamber, $\mathrm{Zn}$ nanowires were first deposited on Si substrates, and then the nanowires were oxidized at different temperatures ranging from 400 to $700{ }^{\circ} \mathrm{C}$ under a pressure of $20 \mathrm{~Pa}$. At $400{ }^{\circ} \mathrm{C}$, well-defined, crack-free $\mathrm{ZnO}$ nanotubes with $60-130 \mathrm{~nm}$ in outer diameter and $30.7 \mathrm{~m}^{2} \mathrm{~g}^{-1}$ BET surface area were synthesized. Different $\mathrm{ZnO}$ nanotubes were synthesized by a chemical bath deposition method (54). Firstly, $\mathrm{ZnO}$ nanoparticles prepared by a sol-gel method were immobilized on fluorine doped tin oxide glass substrate. The solvent on the substrate was removed by heat treatment. Then, the substrate was suspended to grow $\mathrm{ZnO}$ nanotubes in a solution of $0.1 \mathrm{M}$ zinc nitrate hexahydrate and $0.1 \mathrm{M}$ methenamine at $75{ }^{\circ} \mathrm{C}$ for $3 \mathrm{~h}$. The substrate was rinsed with deionized water, immersed into $0.3 \mathrm{M} \mathrm{KOH}$ solution at $80{ }^{\circ} \mathrm{C}$ for $1 \mathrm{~h}$ following drying at 100 ${ }^{\circ} \mathrm{C}$ for $1 \mathrm{~h}$. Highly vertically-aligned, hexagonal $\mathrm{ZnO}$ nanotube arrays with $~$ $650 \mathrm{~nm}$ in diameter were obtained. In addition, the synthesis of $\mathrm{ZnO}$ nanorods and nanodisks by a sol-gel method has been reported $(55,56)$. To obtain $\mathrm{ZnO}$ nanorods, $\mathrm{NaOH}$, zinc acetate, manganese acetate, and sodium dodecyl sulfate were used. $\mathrm{ZnO}$ nanorods with 7-10 $\mathrm{nm}$ in diameter and 200-300 nm in length were grown in the presence of sodium dodecyl sulfate (SDS) as soft template at room temperature (55). The diameter of nanorods decreased with an increase in the molar ratio of $\mathrm{Mn} / \mathrm{OH}$ in the solution. However, the diameter increased when the ratio reached a certain level. The nanorods were not obtained with only manganese acetate or SDS in the solution. Also, the formation of nanorods was only influenced by $\mathrm{Mn}^{2+}$ in the solution. No formation of nanorods was observed by replacing $\mathrm{Mn}^{2+}$ with other cations, such as $\mathrm{Cr}^{2+}, \mathrm{Cu}^{2+}, \mathrm{Co}^{2+}, \mathrm{Ca}^{2+}, \mathrm{Cd}^{2+}$, $\mathrm{Ni}^{2+}, \mathrm{Pb}^{2+}, \mathrm{Fe}^{3+}, \mathrm{Al}^{3+}, \mathrm{Er}^{3+}$, or $\mathrm{Sn}^{4+}$. Zhai et al. (56) reported the synthesis of hierarchical $\mathrm{ZnO}$ nanodisks through a chemical hydrolysis method in a dimethyl sulfoxide (DMSO) $-\mathrm{H}_{2} \mathrm{O}$ system. To obtain $\mathrm{ZnO}$ nanodisks, the concentration of DMSO in the solution was a critical parameter. Nanodisks with a uniform size of ca. $200-300 \mathrm{~nm}$ were formed with $90 \%$ DMSO. The nanodisks were composed of many $20-40 \mathrm{~nm}$ nanocrystallines. Hexagonal nanorings $(\sim 300 \mathrm{~nm}, 40-60 \mathrm{~nm}$ one side diameter), nanoparticles (200-350 $\mathrm{nm}$ in diameter), and microtyres (1.1 $\mu \mathrm{m}$ in diameter) were formed with 60,70 , and $80 \%$ DMSO, respectively. The BET surface area of nanodisks, nanorings, nanoparticles, and microtyres was $37.3,21.9,26.1$, and 12.8 , respectively.

Iron oxides also have been widely used as photocatalysts to remove organic pollutants (57-60). Hematite $\left(\alpha-\mathrm{Fe}_{2} \mathrm{O}_{3}\right)$ is usually used as a photocatalyst due to the visible light absorption capacity $\left(2.1 \mathrm{eV}\right.$ bandgap) $(60,61), \alpha-\mathrm{Fe}_{2} \mathrm{O}_{3}$ was obtained using starch as a capping reagent (61). Ferric hydroxide was synthesized by adding triethyl amine after reaction with $\mathrm{FeCl}_{3}$ and starch solution. After centrifugation and calcination, very uniform $\alpha-\mathrm{Fe}_{2} \mathrm{O}_{3}$ nanoparticles with a narrow size distribution (average particle size of $30 \mathrm{~nm}$ ) were synthesized. BET surface area increased from 24 to $126 \mathrm{~m}^{2} \mathrm{~g}^{-1}$ with increasing precursor $\mathrm{Fe}^{3+}$ concentration. Particle size and shape were influenced by $\mathrm{pH}$ of solution. Zhou et al. (60) reported the synthesis of hematite by thermal dehydration. $\alpha-\mathrm{Fe}_{2} \mathrm{O}_{3}$ nanorods 
with $40 \mathrm{~nm}$ length, $11 \mathrm{~nm}$ width, and $93 \mathrm{~m}^{2} \mathrm{~g}^{-1}$ BET surface area were obtained by heating $\alpha-\mathrm{FeOOH}$ precursors at $300{ }^{\circ} \mathrm{C}$ in air for $1 \mathrm{~h}$.

In addition, metal sulfides have been extensively investigated for photocatalytic degradation of environment pollutants. Recently, CdS, $\mathrm{ZnS}$ and their suspensions have been intensively studied $(14,15,62-64)$. CdS nanocrystalline particles are considered attractive candidates for visible light-induced photocatalysis because they can produce reactive oxygen species, such as superoxide $\left(\mathrm{O}_{2}{ }^{-}\right)$and hydroxyl $\left(\mathrm{OH}^{*}\right)$ radicals in aqueous solution (62). Bao et al. (14) synthesized nanoporous $\mathrm{CdS}$, including nanosheets and hollow nanorods, by a two-step aqueous route. Nanoporous nanosheets with size less than $60 \mathrm{~nm}$ and thickness of $\sim 9 \mathrm{~nm}$ and hollow nanorods with $30 \mathrm{~nm}$ length and $7-14 \mathrm{~nm}$ in outer diameter were obtained by an initial precipitation of nanoporous $\mathrm{Cd}(\mathrm{OH})_{2}$ intermediates following $\mathrm{S}^{2-} / \mathrm{OH}^{-}$ion exchange. Nanopores' diameter and BET surface area of nanosheets were $\sim 3 \mathrm{~nm}$ and $112.8 \mathrm{~m}^{2} \mathrm{~g}^{-1}$, respectively. Yang et al. (63) synthesized visible light-activated, Zn-doped CdS (Zn-CdS) nanostructures by hydrothermal treatment. To obtain $\mathrm{Zn}-\mathrm{CdS}$, an aqueous solution containing $\mathrm{Cd}\left(\mathrm{CH}_{3} \mathrm{COO}\right)_{2}, \mathrm{Zn}\left(\mathrm{CH}_{3} \mathrm{COO}\right)_{2},\left(\mathrm{NH}_{2}\right)_{2} \mathrm{CS}$ (thiourea), and deionized water was autoclaved at $120-180{ }^{\circ} \mathrm{C}$ for several hours. BET surface area and bandgap increased with increasing molar ratio of $\mathrm{Zn} / \mathrm{Cd}$. $\mathrm{Zn}$ doping enhanced photocatalytic activity and improved the stability of CdS.

In comparison with $\mathrm{CdS}, \mathrm{ZnS}$ has relatively large bandgap $(3.6 \mathrm{eV})$, which is a limitation to utilize the visible light portion of the solar spectrum. Therefore, UV light sources were employed to activate $\mathrm{ZnS}$ photocatalysts. $\mathrm{Hu}$ et al. (15) synthesized $\mathrm{ZnS}$ nanoporous nanoparticles by a solution-phase thermal deposition route in the presence of poly( $N$-vinyl-2-pyrrolidone). The spherical monodisperse nanoparticles with $60 \mathrm{~nm}$ diameters and large BET surface area (156.1 $\mathrm{m}^{2} \mathrm{~g}^{-1}$ ) were obtained. Ren et al. (64) prepared $\mathrm{ZnS}$ microspheres consisting of interwoven nano-sheets by hydrothermal conditions using $\mathrm{NaOH}$. The primary particle size ( $3 \mathrm{~nm}$ to bulk) and nanostructure (compact microspheres to nanosheets) were significantly influenced by $\mathrm{NaOH}$ concentration.

\subsection{Novel Methods for Preparation of Nanomaterials through Green Technologies}

\subsubsection{Microwave-Assisted Processing}

The microwave oven was invented by Dr. Percy Spencer after the Second World War from the radar technology developed for the war. The development of a magnetron to generate microwaves of a definite frequency was the most significant step in this invention. Domestic microwave ovens appeared in the consumer markets in 1950. However, microwave technology was not employed in inorganic material synthesis until the late 1990s. It was revealed in 1996 by Komerneni and co-workers that, under similar processing circumstances, preparation of hematite by a microwave hydrothermal reaction is 36 times faster than the conventional hydrothermal synthesis (65). The use of the microwave in chemistry has been seen to improve yields, selectivity and allows conversions that would otherwise be impossible. Since then microwave-assisted synthesis is becoming a widespread 
method to synthesize organic and inorganic nanostructured materials. The major advantage of this technology is that no further annealing is required for developing crystalline materials. Microwave processing is found to be significantly faster compared with the synthesis using a conventional chamber furnace. Researchers at the Dublin Institute of Technology, Ireland have recently developed (Patent publication number $\mathrm{WO} / 2009 / 113045$ A2) a microwave-assisted synthesis of mesoporous titanium dioxide with high surface area $\left(250 \mathrm{~m}^{2} \mathrm{~g}^{-1}\right)$, small particle size $(15 \mathrm{~nm})$ and excellent visible-light activity (up to four times higher than commercial samples) (66). Research into microwave-assisted preparation of nanomaterials has been studied for its effectiveness against more traditional methods. It has been seen that the majority of the other preparation methods such as sol-gel methods require high temperatures $\left(450-1400{ }^{\circ} \mathrm{C}\right)$ and a longer processing time, typically six to eight hours, to obtain crystalline particles, whereas with the addition of the microwave in the preparation, temperatures as low below $250{ }^{\circ} \mathrm{C}$ can be used to produce quality crystalline $\mathrm{TiO}_{2}(67)$. The efficiency of hydrothermal processing in the preparation of particles can be seen in the reduction of time taken to prepare highly crystalline particles as it allows for rapid heating and extremely rapid kinetics of crystallization. Compared to sol-gel processing, the microwave-assisted technique offers an energy efficient, eco-friendly, rapid and convenient method of synthesizing doped and undoped metal oxides such as $\mathrm{TiO}_{2}(68), \mathrm{CuO}$ nanoparticles (69) and copper sulfate nanorods (70). An industrially viable method for the preparation of mesoporous titania nanomaterials for NanoChromic display device applications by the use of microwave processing was reported (66). Spherical aggregates of nanocrystalline titania materials were rapidly prepared using titanium butoxide, deionized water and alcohol at comparatively low microwave power intensity $(300 \mathrm{~W})$ for $2 \mathrm{~min}$ irradiation (Figure 2). The samples prepared via microwave process using an 2.45 GHz industrial microwave oven, CEM Mars 5 (Figure 3) showed a surface area up to $240 \mathrm{~m}^{2} \mathrm{~g}^{-1}$, which was significantly higher than similar traditional sol-gel or commercial samples $\left(40 \mathrm{~m}^{2} \mathrm{~g}^{-1}\right)$.

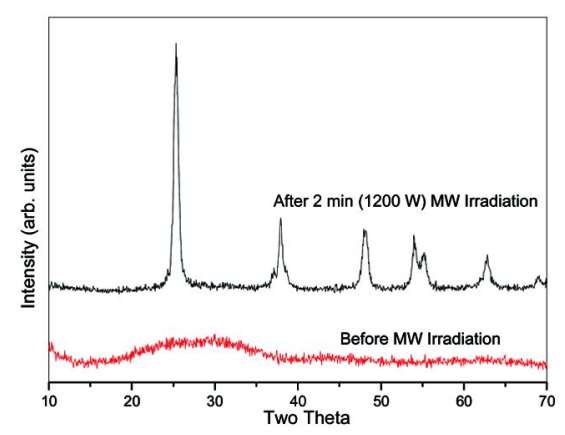

Figure 2. XRD pattern of titania precursor sample before and after microwave irradiation. 


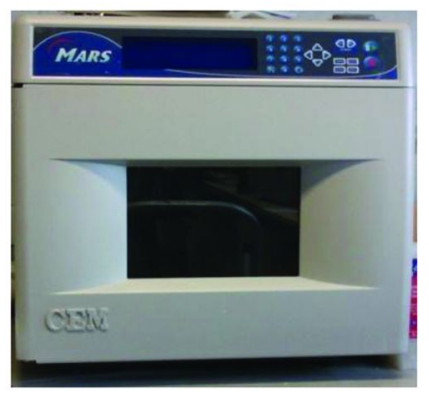

Figure 3. CEM MARS-5 $2.45 \mathrm{GHz}$ Microwave processing facility housed at CREST, Dublin Institute of Technology.

The development of materials that can utilize visible light $(>400 \mathrm{~nm})$ is essential for the effective exploitation of solar energy-driven photocatalysis. Photocatalysis is a reaction that uses light to activate a substance that modifies the rate of a chemical reaction without being involved itself and the photocatalyst is the substance which can modify the rate of chemical reaction using light irradiation. Like above, microwave irradiation can be used in the preparation of visible-light active (VLA) materials which can be used to break down contaminants of interest. Photocatalytic anatase $\mathrm{TiO}_{2}$ has been formed by using a mixed solution of tetrabutyl titanate, hydrogen fluoride (HF) solution and additional water at $200{ }^{\circ} \mathrm{C}$ for $30 \mathrm{~min}$ in a rapid synthesis using microwave-assisted hydrothermal treatment (71). $\mathrm{TiO}_{2}$ nanostructures of various morphologies have been prepared using microwave irradiation as its synthesizing technique. These different patterns are seen to all have different photocatalytic responses when tested for their degradation abilities against methylene blue under ultraviolet light. They also are seen to have a superior photocatalytic rate when compared to the industry standard, Degussa $\mathrm{P} 25 \mathrm{TiO}_{2}$ (72). A simple microwave-irradiation method has been seen in the making of silica-coated $\mathrm{ZnO}$ nanoparticles. These were characterized by X-ray photoelectron spectroscopy (XPS), Fourier transform infrared spectroscopy (FT-IR), high-resolution transmission electron microscopy (HR-TEM), CHN elemental analysis and zeta potential measurements for the presence of $\mathrm{Zn}, \mathrm{O}$ and $\mathrm{Si}$. These particles have certain photocatalytic properties, where the silica effectively inhibits the photocatalytic activity of the $\mathrm{ZnO}$ nanoparticles (73). The use of microwave irradiation has the ability to effectively reduce time and energy used in the making of many different nanomaterials in the area of nanoscience.

\subsubsection{Sonochemical Methods}

Advanced research into the chemical effects of ultrasound radiation has been a rapidly growing research area for the last two decades. An ultrasonic reaction occurs when ultra-sound waves are irradiated in a liquid phase. During such 
an occurence, intense local heating and high pressure are produced (hot spots). These local hot spots initiate and propagate high-energy chemical reactions. There are potentially many benefits to using ultrasonic technology as a strategic synthetic method for making nanomaterials at a low temperature. A number of investigations using ultrasound radiation to synthesize ceramic materials have been explored with potential uses in materials science. For example, the materials group at Trinity College Dublin, prepared superparamagnetic $\gamma-\mathrm{Fe}_{2} \mathrm{O}_{3}$ nanoparticles by using ultrasonic irradiation of an $\mathrm{Fe}$ (II) alkoxide derivative (74, 75). There have been many other studies carried out in the field of sonochemistry in relation to nanoparticles. Sonochemical decomposition of $\mathrm{Fe}(\mathrm{CO})_{5}$ was carried out in the presence of various surfactants, resulting in the production of stable colloids of undecenoate, dodecyl sulfonate, and octyl phosphonate coated $\mathrm{Fe}_{2} \mathrm{O}_{3}$ nanoparticles with a diameter of 5-16 $\mathrm{nm}$ (76). The use of sonochemistry in relation to the synthesis of nanomaterials has been seen to have several effects on the particles produced. One such effect is the different morphologies it can produce and its ability to control the shape of chemicals such as $\mathrm{PbWO}_{4}$ nanostructures (77), $\mathrm{Zn}$ (II)bis(1-(2-pyridylazo)-2-naphthol) $\left(\mathrm{Zn}(\mathrm{PAN})_{2}\right)$ complex nanorods (78), porous $\mathrm{Cu}_{2} \mathrm{O}$ nanospheres (79), and single-crystalline $\mathrm{PbF}_{2}$ nanorods $(80)$. Increasing ultrasound irradiation power can also be seen to decrease the particle size of nanoparticles such as $\mathrm{ZnO}(81)$. Nanosize $\mathrm{ZnO}$ was similarly prepared using a simple synthesis method using zinc acetate as a precursor and 1, 3-propanediol as a solvent using ultrasound sonication (82). Previously, a novel sonochemical process in which the hydrolysis of tetraisopropyl titanate, a titanium alkoxide, under high-intensity ultrasonic irradiation $(20 \mathrm{KHz}$, $100 \mathrm{~W} \mathrm{~cm}^{-2}$ ) at $90{ }^{\circ} \mathrm{C}$ for $3 \mathrm{hr}$ was used to directly prepare anatase nanocrystalline $\mathrm{TiO}_{2}(83)$. The above results show that sonochemical processing has the ability to produce functional materials at a low temperature in a shorter time compared to conventional synthetic methods.

\section{Applications of Nanomaterials for the Green Nanotechnology}

\subsection{Water, Air, and Soil Remediation and Energy Application}

Most formal definitions of nanotechnology revolve around the study and control of phenomena and materials at length scales below $100 \mathrm{~nm}$. In October 2011 the European Commission adopted the definition of a nanomaterial as a natural, incidental or manufactured material containing particles, in an unbound state or as an aggregate or as an agglomerate and where, for $50 \%$ or more of the particles in the number size distribution, one or more external dimensions is in the size range $1 \mathrm{~nm}-100 \mathrm{~nm}(84)$. Today, nanotechnology efforts are centered at controlling matter at near-atomic scales to produce unique or enhanced materials, products and devices, optimizing the fabrication processes, proposing innovative solutions for environmental remediation/protection, enhancing the perspectives for optimum exploitation of renewables and contributing to economic development. In addition, there is an important trend of increasing societal concerns about the safety aspects of nanomaterials and rational use of related products. Aimed at answering the above questions and building on existing work 
on green chemistry and engineering, green nanotechnology is almost as broad as nanotechnology, aiming at developing technology (made in a green way) that can tackle environmental and energy challenges, for example with new solar energy and water treatment technologies (85).

\subsubsection{Advanced Oxidation Processes Involving Innovative Nanocatalysts for Environmental Repair}

Nanotechnology can guarantee cleaner drinking water providing important achievements that constitute the basis for a sustainable and cost-effective, solar energy technology for water treatment (86). Very recently, special interest was expressed in exploiting solar energy and recent advances in nano-engineered titania photocatalysts and membranes for the destruction of extremely hazardous compounds in water (87), including novel emerging pollutants (pharmaceuticals, toxins, hormones) of high environmental and health impact (88-90). Thus, the synthesis of highly reactive $\mathrm{TiO}_{2}$ photocatalysts has been reported by means of an efficient sol-gel method combined with the removal of larger aggregates, proper aeration and optimization of the calcination temperature (88). In addition, an innovative sol-gel synthesis based on the self-assembling template method has been also applied to synthesize mesoporous anion doped $\mathrm{TiO}_{2}$ with $\mathrm{N}-\mathrm{F}, \mathrm{S}$ and $\mathrm{C}$ hetero-atoms using suitable surfactants and reagents, to improve simultaneously the structural, morphological and electronic properties of $\mathrm{TiO}_{2}$ nanomaterials and achieve anion doping of titania with high visible light photo-induced reactivity $(31,88,89)$. Co-doping of $\mathrm{TiO}_{2}$ by $\mathrm{N}$ and $\mathrm{F}$ anions was achieved by a modified sol-gel method using a nonionic fluorosurfactant, as pore template material and fluorine source combined with ethylenediamine as nitrogen source (91). Moreover, the synthesis of m-modified $\mathrm{TiO}_{2}$ was optimized using combustion sol-gel synthesis employing urea as nitrogen source (92). The evaluation of the photocatalytic activity of the above nanostructured catalysts for water detoxification from cyanotoxin compounds released by cyanobacteria blooms (e.g. microcystin-LR/MC-LR, one of the most common and toxic congeners) as well as taste and odor pollutants released by cyanobacteria, geosmin (GSM) and 2-methylisoborneol (2-MIB) was performed using UVA, solar and visible light (93). This work was further expanded to water detoxification by endocrine disrupting compounds (EDCs) such as bisphenol A and 17ß-estradiol (94). Finally, composite carbon nanotubes/titania nanostructures were developed on well-aligned carbon nanotubes (CNTs) produced by means of chemical vapor deposition (CVD) using surfactant-stabilized $\mathrm{Fe}_{3} \mathrm{O}_{4}$ particles and anodized alumina disks as templates. All these innovative approaches have been implemented by integrating extensive R\&D efforts spanning a wide range of interdisciplinary activities from the development of novel nanomaterials and membranes to reactor engineering and analytical methods for water pollutants of emerging concern as well as pilot plant scale studies and cost analysis for water purification (95-97).

Besides the establishment and validation of methods for detection of emerging contaminants, nanotechnology also permits the development of smart 
instruments (sensors). Thus, an innovative multi-walled carbon nanotube (MWCNT) electrochemical biosensor was developed (98) for monitoring MC-LR in drinking water supplies. This novel approach was devised relying on the combination of the work carried out on the functionalization of carbon nanotubes with the MC-LR analytical determination.

Using innovative sol-gel chemistry and electrochemistry, UV and visible-light responding nanostructured titania based catalysts can be developed that are highly-efficient in photoinduced multi-dynamic processes. This comprises advanced oxidation processes with applications outside the field of water detoxification including self-cleaning photoinduced superhydrophilicity (99) and self-sterilizing (100) as well as atmospheric depollution from volatile organic compounds (VOCs) and nitrogen oxides (101). Thus, optimized $\mathrm{N}, \mathrm{F}-\mathrm{TiO}_{2}$ films were exploited as immobilized photocatalysts for air purification and specifically in the photocatalytic oxidation of NOx gas pollutants under UV and visible light, exhibiting very efficient photocatalytic activity under visible-light excitation (102). A maximum percentage of NO removal equal to $24.2 \%$, one of the best reported up to now for visible-light photocatalysis, was reported together with excellent stability and reproducibility in successive light on-off experiments. Moreover, very promising photocatalytic materials (ECT-1023t, GOT composites and $\mathrm{N}-\mathrm{TiO}_{2}$ ) embedded into polymeric aerogel type hollow fibers (95) were applied for NOx and volatile organic compounds (VOCs) abatement in air in a continuous-flow photocatalytic air treatment process in which the gas stream was forced to flow through the pore structure of light transparent fibers in contact with the photocatalysts.

Besides water and air remediation, advanced oxidation processes and especially photocatalysis are also capable of organic pollutants removal in soil. In a recent study (103), a pulsed-discharge plasma- $\mathrm{TiO}_{2}$ catalytic (PDPTC) technique was proposed to investigate the remediation of p-nitrophenol (PNP) contaminated soil, by combining $\mathrm{TiO}_{2}$ photocatalysis and nonthermal discharge plasma, where catalysis of $\mathrm{TiO}_{2}$ is driven by the pulsed discharge plasma. In addition, removal of alkylphenols from polluted sites using surfactant-assisted soil washing and photocatalysis was observed, in the presence of $\mathrm{TiO}_{2}$ dispersions irradiated with simulated solar light (104).

\subsubsection{Combating Climate Change}

Although there is no single solution to the challenge of reducing greenhouse gas emissions, nanotechnology can help to combat climate change by improving efficiency and bringing new energy sources (developing low-carbon forms of energy) to the market. This represents an enormous opportunity for the international community. A recent report lists five areas where nanotechnology can make a difference: fuel additives to increase the efficiency of diesel engines; photovoltaic technology for solar cells; the hydrogen economy and fuel cells; batteries and supercapacitors for energy storage; and improved insulation for houses and offices (105). 
Nanotechnology offers the promise of better solar cells. In fact, based on a process mimicking natural photosynthesis in plants that separates the reaction centers of light absorption and charge transport/storage processes, easily processable and cost-effective solar cells (dye-sensitized solar cells-DSCs) can be developed, based on the dye-sensitization approach $(106,107)$. In this device, the active photoelectrode consists of a thin layer of mesoporous nanostructured wide band-gap semiconductor $\left(\mathrm{TiO}_{2}\right.$ has been almost exclusively used as a semiconductor in high performance DSCs) deposited onto a conducting substrate and a monolayer of a visible light-absorbing dye chemically adsorbed onto the nanoparticles of the semiconductor. This new type of nanotechnology-based third generation photovoltaic (hybrid organic-inorganic) currently presents power conversion efficiencies $(\eta)$ of the order of $12 \%(108,109)$. Coordinated efforts including the participation of partners from both academia and private companies are now under intensive investigation at a global level, in order to endow the device with a solid character as well as with enhanced life time and stability, features that make this technology a very promising alternative to classical solid state PVs (110-112).

\subsection{Photocatalytic Disinfection of Water}

Water is an important natural resource and safe drinking water is vital for human existence and good quality of life. Clean water resources are becoming depleted due to population growth, over-use of resources and climate change. Since the adoption of the Millennium Development Goals (MDG), the WHO/UNICEF Joint Monitoring Programme for Water Supply and Sanitation has reported on progress towards achieving Target $7 \mathrm{c}$ : "reducing by half the proportion of people without sustainable access to safe drinking water and basic sanitation" (112). It was reported that, as of 2010, the target for drinking water has been met; however, 780 million people are still without access to an improved drinking water source. Many more are forced to rely on sources that are microbiologically unsafe, leading to a higher risk of contracting waterborne diseases, including typhoid, hepatitis A and E, polio and cholera (113-116). Although the MDG drinking-water target refers to sustainable access to safe drinking water, the MDG indicator - "use of an improved drinking water source" - does not include a measurement of either drinking water safety or sustainable access. This means that accurate estimates of the proportion of the global population with sustainable access to safe drinking water are likely to be significantly lower than estimates of those reportedly using improved drinking water sources. It is estimated that, at the current rate of progress, 672 million people will not use improved drinking water sources in 2015. It is likely that many hundreds of millions more will still lack sustainable access to safe drinking water.

Piped-in water supplies are a long term goal and interventions to improve water supplies at the source (point of distribution) have long been recognized as effective in preventing waterborne disease. Recent reviews have shown household-based (point-of-use) interventions to be significantly more effective than those at the source for the reduction of diarrhoeal diseases in developing 
regions (possibly due to contamination of water between collection and use). As a result, there is increasing interest in such household-based interventions that can deliver the health gains of safe drinking water at lower cost (116). Household water treatment and safe storage (HWTS) is one option for improving the quality of water for consumption within the home, especially where water handling and storage is necessary and recontamination is a real risk between the point of collection and point of use. Limitted access to nearby sources, unreliable piped supplies and reliance on rainwater are all factors that make household storage a necessity. Living conditions in many humanitarian crises also call for effective HWTS. The practice of household water treatment and safe storage can help improve water quality at the point of consumption, especially when drinking water sources are distant, unreliable or unsafe. However, HWTS is a stop-gap measure only and does not replace the obligation of a service provider to supply access to safe drinking water. Household water treatment (HWT) methods include boiling, filtration, adding chlorine or bleach, and solar disinfection.

In 2008, Clasen and Haller reported on the cost and cost effectiveness of household based interventions to prevent diarrhoea (117). They compared: chlorination using sodium hypochlorite following the "Safe Water System" (SWS) developed and promoted by the US Centers for Disease Control and Prevention (CDC); gravity filtration using either commercial "candle" style gravity filters or locally fabricated pot-style filters developed by Potters for Peace; solar disinfection following the "SODIS" method in which clear 2 L PET bottles are filled with raw water and then exposed to sunlight for 6 - $48 \mathrm{~h}$ (Figure 4); and flocculation disinfection using Procter \& Gambles PUR ${ }^{\circledR}$ sachets, which combine an iron-based flocculant with a chlorine-based disinfectant to treat water in $10 \mathrm{~L}$ batches. They concluded that household-based chlorination was the most cost-effective. Solar disinfection was only slightly less cost-effective, owing to its almost identical cost but lower overall effectiveness. Given that household-based chlorination requires the distribution of sodium hypochlorite, solar disinfection has a major advantage in terms of non-reliance on chemical distribution.

Sunlight is freely available on Earth and the combined effects of heat and UV from the sun can inactivate pathogenic organisms present in water. Of course, there are a number of parameters which affect the efficacy of the solar disinfection (SODIS) process, including the solar intensity, temperature, and the level and nature of the contamination (some pathogens are more resistant to SODIS than others). One approach to SODIS enhancement is the use of heterogeneous photocatalysis.

In 1985, Matsunaga et al. reported the inactivation of bacteria using $\mathrm{TiO}_{2}$ photocatalysis (118). To date, there have been many papers published presenting results on the photocatalytic inactivation of microorganisms including bacteria, viruses, protozoa, fungi and algae. In 1999, Blake et al. published an extensive review of the microorganisms reported to be inactivated by photocatalysis (119). More recently, McCullagh et al. reviewed the application of photocatalysis for the disinfection of water contaminated with pathogenic microorganisms (120). Malato et al. have published an extensive review on the decontamination and disinfection of water by solar photocatalysis (121) and, in 2010, Dalrymple et al. reviewed the modeling and mechanisms of photocatalytic disinfection (122). 

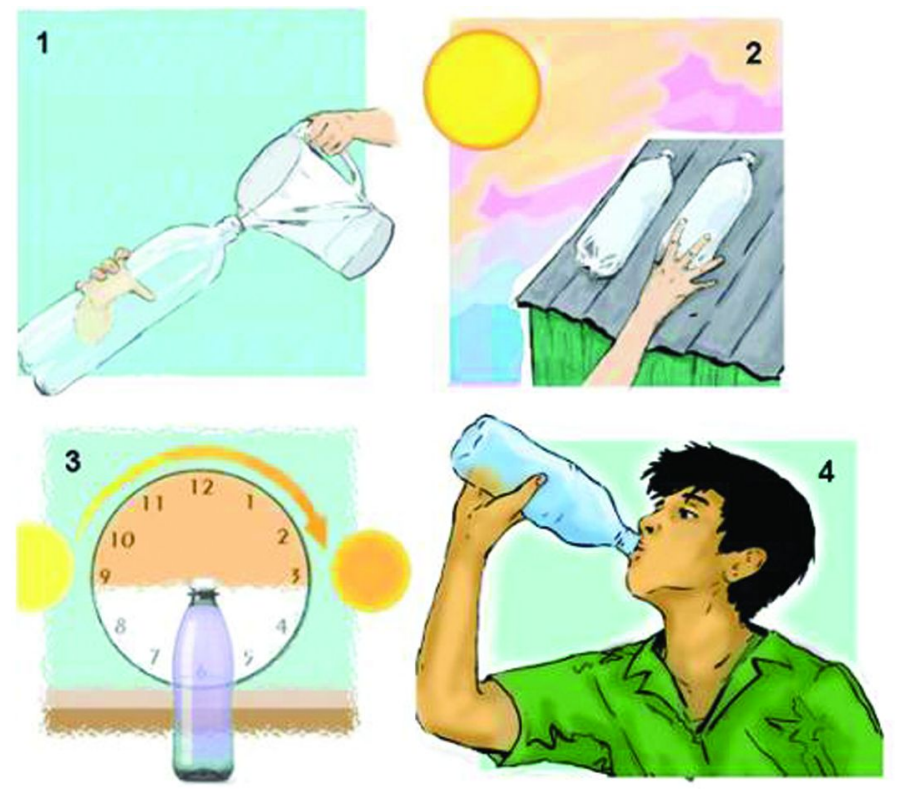

Figure 4. Simple protocol for the solar disinfection of water SODIS process. (courtesy of Dr. Kevin McGuigan, Royal College of Surgeons in Ireland, drawn by Maria Boyle).

In most studies, the hydroxyl radical is suggested to be the primary species responsible for microorganism inactivation. Some researchers have examined the role of other reactive oxygen species, such as $\mathrm{H}_{2} \mathrm{O}_{2}$ and $\mathrm{O}_{2}{ }^{-*}$ - in disinfection (123). Reactive oxygen species cause fatal damage to microorganisms by disruption of the cell membrane and/or by attacking DNA and RNA (119). Other modes of action include damage to the respiratory system within the cells (124). Some researchers have attributed cell death to lipid peroxidation of bacterial cell membrane (125-127). The peroxidation of the unsaturated phospholipids that are contained in the bacterial cell membrane causes loss of respiratory activity (124) and/or leads to a loss of fluidity and increased ion permeability (126). This is suggested to be the main reason for cell death. Other researchers suggested that the cell membrane damage can open the way for further oxidative attack of internal cellular components, ultimately resulting in cell death (128).

The photocatalyst (most commonly $\mathrm{TiO}_{2}$ ) can be used as an aqueous suspension or it may be immobilized on a supporting substrate. Most studies report that suspension reactors are more efficient due to large surface area available for the reaction and no mass transfer limitations $(129,130)$. The main drawback of using nanoparticles in suspension is the requirement for post-treatment separation and recycling of the catalyst, making the treatment more complex and expensive. Treatment systems utilizing immobilized $\mathrm{TiO}_{2}$ have gained more attention. There are a range of methods available for the preparation of immobilized photocatalyst films on supporting substrates (129).

It is clear from the literature that photocatalytic disinfection is more effective than UVA treatment alone (131-134). However, scale-up and testing under real 
sun conditions may show different results depending on the reactor configuration and on the model organism being tested. For example, Alrousan et al. tested solar photocatalytic (SPC-DIS) and solar disinfection (SODIS) of water at pilot scale using different reactor configurations with and without immobilized $\mathrm{TiO}_{2}$ (Evonik Aeroxide P25). The model organism used was E. coli. The use of compound parabolic collectors improved the SODIS and SPC-DIS of water, however, the improvement was less significant compared to the improvements reported previously for SODIS in static batch reactors. Kinetic fitting yields a log-linear component (1st order rate constant). The following order was found for $\mathrm{k}$ where coated refers to $\mathrm{TiO}_{2}$ coating and the equals sign indicates no significant difference; uncoated external - coated internal $\geq$ double coated tube $\geq$ uncoated double tube. It is known that $E$. coli is inactivated by SODIS and it may be a 'soft' target for comparing the effectiveness of SODIS vs SPC-DIS. Nevertheless, photocatalysis presents advantages in terms of the non-recovery of inactivated organisms and the inactivation of SODIS resistance organisms (135).

Conventional $\mathrm{TiO}_{2}$ is a UV absorber and will only utilize the around $4 \%$ of the solar spectrum. Much research effort has been placed on increasing the solar efficiency of $\mathrm{TiO}_{2}$ by doping to shift the optical absorption towards the visible region of the electromagnetic spectrum. Different approaches have been attempted including doping the $\mathrm{TiO}_{2}$ with metal ions. According to the literature, one of the more promising approaches to achieve visible light activity is doping with non-metal elements as reported in the previous section. However, the number of publications concerning the photocatalytic activity of these materials for the inactivation of microorganisms is limited. The UV activity of undoped $\mathrm{TiO}_{2}$ may be greater than the visible light activity of a doped material. Therefore, for solar applications, the efficiency should be tested under simulated solar irradiation or under real sun conditions. Rengifo-Herrera and Pulgarin reported on the photocatalytic activity of N, S co-doped and $\mathrm{N}$-doped commercial anatase (Tayca TKP 102) $\mathrm{TiO}_{2}$ powders towards phenol oxidation and E. coli inactivation (136). However, these novel materials did not present any enhancement as compared to Degussa P-25 (now Evonik Aeroxide P25) under simulated solar irradiation. They suggest that while the $\mathrm{N}$ or $\mathrm{N}, \mathrm{S}$ co-doped $\mathrm{TiO}_{2}$ may show a visible light response, the localized states responsible for the visible light absorption do not play an important role in the photocatalytic activity.

More research is required to determine if visible-light active materials can deliver an increase in the efficiency of photocatalysis under solar irradiation. Improvements in photocatalytic reactor design could make this technology available at low cost for the solar disinfection of water in developing regions.

\section{Selective Photocatalysis for the Decomposition of Target Contaminants}

\subsection{Selectivity Issue in $\mathrm{TiO}_{2}$ Photocatalysis}

Photocatalysis has become a major discipline and research area due to the mutual enrichment of researchers in many different fields. Since the photocatalytic process is governed by a free radical mechanism, it is characterized 
with non-selective attack on organic chemicals in water. Decomposition rate of many organic molecules was reported to be more or less similar (137). The non-selectivity of the process sounds great since re-designing photocatalysts is not required for the decomposition of a certain contaminant. However, the poor selectivity also implies that the oxidation does not differentiate between highly toxic contaminants and less toxic contaminants in water (138). When a new $\mathrm{TiO}_{2}$ photocatalyst is synthesized, its reactivity is evaluated with a probe chemical in pure water to compare it with a benchmark catalyst (e.g., Degussa P-25 $\mathrm{TiO}_{2}$ nanoparticles) and mechanisms for the enhanced reactivity are also investigated (139). This is a common practice in the area. However, an important issue has been invoked: would the catalyst work for the decomposition of such a probe chemical in natural water matrix containing co-existing chemicals, in particular natural organic matter (NOM)? Typical source water contains low concentrations of highly toxic organic substances (e.g., anthropogenic chemicals) together with high concentrations of less toxic naturally present organic matter (i.e., NOM). As shown in Figure 5, the non-selective nature of $\mathrm{TiO}_{2}$ photocatalysis comes under criticism when the process is applied for water treatment to finally polish the effluent from treatment plants. Target contaminants have to compete with abundant NOM for catalytic sites and hydroxyl radicals (140). The nonspecific sorption of NOM inhibits the sorption of target chemicals and also contributes to fouling of the catalyst surface. These significantly decrease the oxidation rate of target chemicals.

\subsection{Current Strategies for Selectivity Enhancement}

Prevention of the nonspecific sorption and oxidation of coexisting organic chemicals at the $\mathrm{TiO}_{2}$ surface (e.g., NOM, organic interferents, proteins, microorganisms, and any organic chemicals other than target chemicals) is of interest (141-147). Operational parameters, including temperature, $\mathrm{pH}$, residence time, solvent, and UV wavelength, can change the degradation ratio of more than two competing chemicals (138). Methods for synthesizing new $\mathrm{TiO}_{2}$ materials with controlled physical and chemical properties (e.g., particle size, crystal size and phase, and surface structure) can also provide many pathways to the preferential oxidation (138). Photocatalysts can also be specially designed for selectivity. This includes doping with noble metals, coating with a specific material, impregnation onto inert organic/inorganic domains, and chemical imprinting $(138,144-147)$. Mixing activated carbon and $\mathrm{TiO}_{2}$ particles was found to increase the degradation rate of phenol (148). Coating photocatalysts with a material that has specific affinity towards a certain contaminant (or a group of contaminants) can decompose the target contaminant selectively. In most cases, coating materials are molecules which have hydrophobic moieties to accommodate sorption of hydrophobic contaminants (149). There is a sorption-and-shuttle approach, where sorption of contaminants on organic or inorganic domains located closely to $\mathrm{TiO}_{2}$ is followed by their diffusion from the adsorptive sites to the photocatalytic sites (146). Predesigned immobile organic molecular recognition sites can also be introduced to inert domains in the vicinity of photocatalysts to facilitate the selective adsorption (150). Another new method 
is to imprint cavities of target molecules on the $\mathrm{TiO}_{2}$ surface (151). However, all of the approaches are either too general or too specific to practically apply to water treatment (note Figure 5). For example, when $\mathrm{TiO}_{2}$ is modified to increase hydrophobicity, it adsorbs and decomposes preferentially a group of hydrophobic contaminants. When $\mathrm{TiO}_{2}$ is functionalized with a chemical marker towards a specific contaminant, it exhibits an ultimate selectivity only to the contaminant. When a target changes, the chemical marker should be replaced accordingly. The chemical functionalization is case-specific and it is also not an easy task. Only few studies aiming at achieving preferential photocatalytic degradation in mixed streams, have been reported.

\section{Source water Main water treatment plant $\quad$ Photocatalytic process}

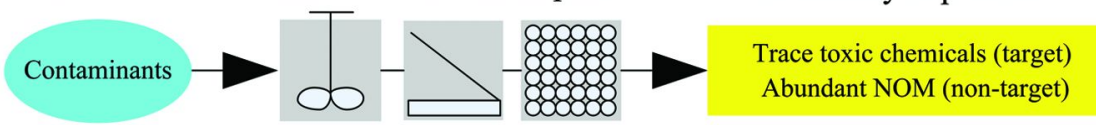

Figure 5. Application of $\mathrm{TiO}_{2}$ photocatalysis to water treatment to polish the effluent from a main water treatment facility composed of coagulation/flocculation-sedimentation-filtration. Since conventional water treatment plants do not have a capability to remove toxic organic chemicals, the photocatalytic process, as a tertiary treatment option, should focus on the destruction of toxic organic chemicals remaining in the effluent.

\subsection{Prospects and Research Direction}

Selective decomposition of target chemicals can be achieved by controlling their preferential transport to the $\mathrm{TiO}_{2}$ surface, considering the heterogeneous nature of the catalytic process. Selection by size has been researched by developing innovative photocatalytic materials with well-defined specific porous structures $(147,152-154)$. As an example, incorporation of $\mathrm{TiO}_{2}$ particles into sheet silicates of clay was suggested (152). Only molecules that are smaller than the distance between adjacent sheet layers are allowed to contact with the incorporated $\mathrm{TiO}_{2}$ (153). Similarly, $\mathrm{TiO}_{2}$ nanoparticles are grafted onto the surface of mesoporous silicates (154). They can also be encapsulated with a porous $\mathrm{SiO}_{2}$ shell, where molecules larger than the pore size of $\mathrm{a} \mathrm{SiO}_{2}$ shell (e.g., macromolecules and NOM) are excluded from the physical contact with core $\mathrm{TiO}_{2}$ particles (155). In many cases, however, the encapsulated $\mathrm{TiO}_{2}$ catalysts exhibit low reactivity due to limitations in light penetration and mass transfer. Detailed research studies are needed to find ways of enhancing both the selectivity and the reactivity of such composite materials, including precise control of the mesoporous and microporous structure of a shell, fabrication of an ultrathin and uniform layer with high mechanical stability, encapsulation of individual $\mathrm{TiO}_{2}$ particle with a shell, and introduction of a void space between core particles and a shell layer. As discussed, common approaches for the size exclusion have required introduction of a secondary material with a well-defined porous structure. Selection of the second material might have been based on the easiness of processing and controlling its porous structure. This can be explained by the 
wide use of silicates in many applications $(147,154)$. Meanwhile, there has been no attempt to use porous $\mathrm{TiO}_{2}$ photocatalysts for the size exclusion. This is because synthesis and control of the porous structure of $\mathrm{TiO}_{2}$ is not as easy as that of $\mathrm{SiO}_{2}$. A pure $\mathrm{TiO}_{2}$ catalyst with an engineered porous structure, when properly designed, is expected to work for the size exclusion, without introduction of any other complex physical and chemical modifications or aids. This would comply with the green engineering and chemistry principle. An engineered $\mathrm{TiO}_{2}$ photocatalyst with controlled properties through innovative material design and processing can serve as an excellent green material for the selective destruction of target contaminants in water.

\section{Reactive Oxygen Species (ROS) in Semiconductor Photocatalysis}

\subsection{Generation of ROS}

Semiconductor photocatalysis has shown tremendous promise for the environmental remediation of an extensive number of pollutants and toxins in water and air streams. Photoexcitation of a semiconductor material can promote an electron from the valence band (VB) to the conduction band (CB) resulting in an electron-hole pair. In competition with recombination the electron can act as a reducing entity and the hole as an oxidizing entity. The VB and CB positions are critical to the effectiveness and economic feasibility of semiconductor photocatalytic materials for water purification. The energy difference between the VB and CB dictates the wavelength of irradiation required for photoexcitation. Large band gaps require higher energy UV irradiation, while semiconductor materials with smaller band gaps can be photoexcited with lower energy visible light irradiation. Photoexcitation with visible light has a significant economic advantage because of the high cost associated with generating the UV light required for activating materials with large band gaps. Doping of $\mathrm{TiO}_{2}$ materials can extend the absorbance into the visible light range, but the semiconductor photocatalytic reaction pathways initiated by UV and visible light can involve significantly different processes (156). Another critical factor is the oxidation and reduction potential of the hole and electron (band position). The VB and CB positions as well as band gaps for a number of common semiconductor materials are summarized in Figure 6 (157).

A variety of ROS can be produced during semiconductor photocatalysis. ROS are central to the semiconductor photocatalytic and advanced oxidative water treatment technologies $(158,159)$. Hydroxyl radical $\left({ }^{\circ} \mathrm{OH}\right)$, superoxide anion radical $\left(\mathrm{O}_{2}{ }^{\circ}\right)$, singlet oxygen $\left({ }^{1} \mathrm{O}_{2}\right)$ and hydrogen peroxide $\left(\mathrm{H}_{2} \mathrm{O}_{2}\right)$, can be produced during semiconductor photocatalysis but the production and role of the different ROS are dependent on the photocatalyst, reaction conditions and target compound. UV $\mathrm{TiO}_{2}$ photocatalysis has been extensively studied and hydroxyl radical is generally believed to be responsible for the primary degradation of target pollutants. Visible light initiated (VLA) photocatalysis typically does not possess the oxidation potential required for the direct formation of hydroxyl radical and thus superoxide anion radical and singlet oxygen appear to play 
important roles in the degradation processes associated with VLA photocatalysis. Ultimately, the VB and CB positions are critical to the effective production of ROS and the economic feasibility of semiconductor photocatalytic materials for water purification.

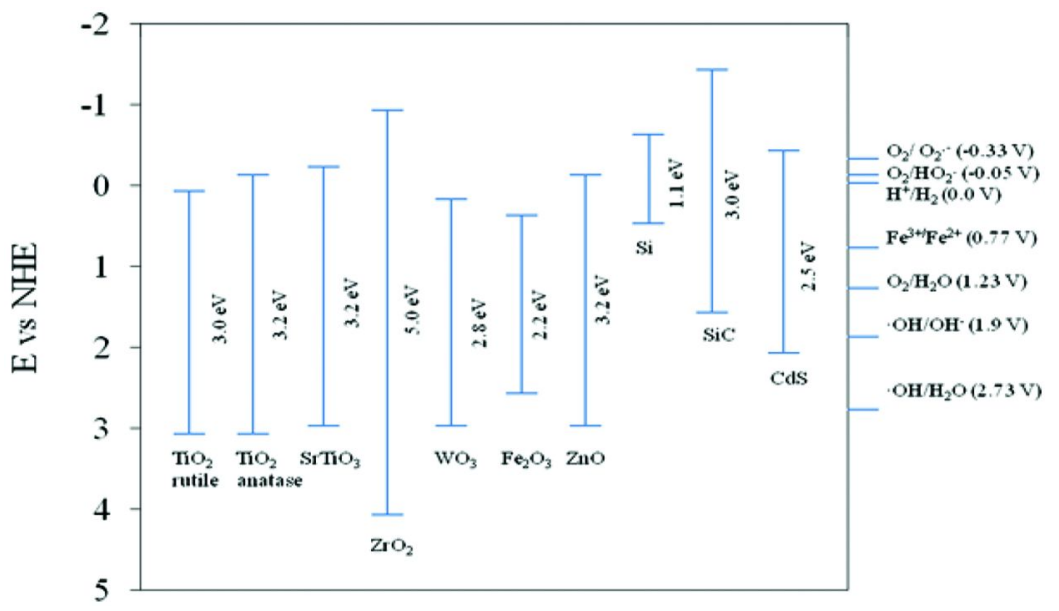

Figure 6. VB and CB positions, band gaps for a number of common semiconductor materials at $\mathrm{pH} 0$. The energy scale is referenced by normal hydrogen electrode (NHE).

\subsection{Roles of ROS during Photocatalysis}

The actual ROS produced during semiconductor photocatalysis depends on the band edge position of semiconductors. Among the ROS, ${ }^{\cdot} \mathrm{OH}$ is the most powerful oxidant and is primarily responsible for the degradation processes during UV photocatalysis in aqueous solution $(160,161)$, and advanced oxidation technologies $(162,163)$. Hydroxyl radical reacts by the addition to double and triple bonds, and aromatic rings, hydrogen-atom abstraction from $\mathrm{C}(\mathrm{sp} 3)-\mathrm{H}$ bonds, and electron transfer with most organic compounds and many inorganic substrates often at nearly diffusion-controlled rates (164). Singlet oxygen, superoxide anion radical, and hydrogen peroxide have lower oxidation potentials than hydroxyl radical, however these species can still lead to the remediation of a variety of pollutants and toxins. The lower oxidation of these species can lead to better selectivity, which can be advantageous for treatment of solutions containing innocuous substrates such as dissolved organic matter, which can compete for and quench hydroxyl radical. $\mathrm{H}_{2} \mathrm{O}_{2}$ and singlet oxygen are generally formed as secondary oxidants but their specific impact in the UV and VLA semiconductor photocatalysis are still not clear. Singlet oxygen can be produced through a photosensitized process and from the reduction of superoxide anion radical, while hydrogen peroxide can be generated from disproportionation of superoxide anion radical and combination of two hydroxyl radicals. Hydroperoxide is commonly employed for remediation through $\mathrm{UV} / \mathrm{H}_{2} \mathrm{O}_{2}$ disinfection processes, Fenton-type 
reactions and Haber-Weiss reactions. $\mathrm{O}_{2}{ }^{--}$can act as a oxidizing or reducing agent depending on the reactivity of the target substrate. The role of $\mathrm{O}_{2}{ }^{-}$especially in VLA photocatalysis is not well understood (165).

\subsection{Measurement of ROS}

Accurate determination of ROS can be challenging because of their high reactivities, short lifetimes and the requirement for specialize equipment. Direct measurement of $\cdot \mathrm{OH}$ is not feasible given the short wavelength absorbance and short lifetime. Common methods for detection and measurement of hydroxyl radical include monitoring of initial reaction products, use of trapping agents and competition (166). The formation of hydroxyl radical products with absorbance from $\sim 260-700 \mathrm{~nm}$ can be directly monitored by transient absorption spectroscopy and absolute rate constants can be extracted by varying the concentration of substrate. Trapping experiments and competition kinetics employ probe compounds with known hydroxyl radical selectivity and reactivities. A number of simple compounds, including t-butanol and formic acid, have been added as hydroxyl radical inhibitors during photocatalysis to access the role of hydroxyl radical in the observed degradation of a target compound. A decrease in the degradation upon addition of a hydroxyl radical inhibitor implies hydroxyl radical plays an important role in the degradation process. While inhibitors are effective for a qualitative assessment, trapping of hydroxyl radical can provide an accurate determination of the concentration and production rate of hydroxyl radical. Hydroxyl radical spin traps produce a spin adducts which can be measured by electron spin resonance (ESR) spectroscopy $(167,168)$. Terephthalic acid and coumarin react with hydroxyl radical to yield adducts with characteristic fluorescence $(169,170)$. These fluorescence probes are easy to use and excellent for quantification of hydroxyl radical in a variety of systems.

Singlet oxygen is in an excited state unlike the other ROS mentioned earlier. While it requires specialized equipment it is possible to measure the presence of singlet oxygen directly based on the phosphorescence at $1270 \mathrm{~nm}$ of the ${ }^{1} \Delta_{\mathrm{g}}$ state (171). Another challenge in measuring singlet oxygen during photocatalysis is its short lifetime in aqueous media. 1,4-diazabicyclo[2.2.2] octane (DABCO), azide, and furfuryl alcohol are used to probe singlet oxygen reactions. Addition of these probes to the reaction solution will quench singlet oxygen and inhibit reactions with target substrates. The generation rate and steady-state concentration of ${ }^{1} \mathrm{O}_{2}$ can be measured by using furfuryl alcohol as a probe (172). Thus, simple addition of a singlet oxygen quencher can provide qualitative evidence for the involvement of singlet oxygen. Another way to probe the role of ${ }^{1} \mathrm{O}_{2}$ during photocatalysis is to run the experiment in water and in heavy water $\left(\mathrm{D}_{2} \mathrm{O}\right)$. The lifetime of singlet oxygen in $\mathrm{D}_{2} \mathrm{O}$ is $\sim 20$ times longer than in $\mathrm{H}_{2} \mathrm{O}$, thus singlet oxygen mediated processes are dramatically enhanced in $\mathrm{D}_{2} \mathrm{O}$ compared to $\mathrm{H}_{2} \mathrm{O}$. Singlet oxygen production has also been monitored by ESR spectroscopy using a trapping agent (173).

Simple reliable colorimetric methods based on peroxidic-type reactions are commonly used for the detection of $\mathrm{H}_{2} \mathrm{O}_{2}$, i.e., the $\mathrm{I}_{3}^{-}$method is based on the spectrophotometric determination of formed $\mathrm{I}_{3}^{-}$, when $\mathrm{H}_{2} \mathrm{O}_{2}$ is mixed with a 
concentrated $\mathrm{I}^{-}$solution. The dimerization of p-hydroxyphenyl acetic acid and enzymatic-colorimetric method are also employed for $\mathrm{H}_{2} \mathrm{O}_{2}$ measurement (174). Catalase has also been used to assess the involvement of hydrogen peroxide in oxidative and biological systems. The involvement of superoxide anion radical can be assessed using competition kinetics employing benzoquinone and superoxide dismutase. Electron spin resonance spectroscopy using a spin trap (175), a luminal chemiluminescent probe compound (176), the combination of reduction of 2,3-bis(2-methoxy-4-nitro-5-sulfophenyl)-2H-tetrazolium-5-carboxanilide and superoxide dismutase method (177) have been used to monitor the production of superoxide anion radical. While there is an extensive number of techniques for measuring and assessing the production of ROS, semiconductor photocatalysis involves heterogeneous systems, which can complicate measurements and limit the use of spectroscopic methods. Accurately determining the production and understanding the interplay among ROS generated under specific semiconductor photocatalytic conditions is critical for practical water treatment applications.

\section{Conclusions}

In conclusion, this book chapter summarizes the preparation of various nanostructured photocatalysts, such as titanium dioxide, zinc oxide, iron oxide, and metal sulfides, by conventional synthesis methods including sol-gel methods, hydrothermal methods, and ball milling methods. Novel processing technologies, such as microwave-assisted and sonochemical methods, were also described for the synthesis of different nanomaterials. By these two latter methods, desirable functional nanomaterials can be produced at lower temperature and in shorter time compared to conventional synthetic methods. With respect to the applications of nanomaterials for environmental remediation, water detoxification, air purification, and photocatalytic disinfection, as well as selectivity of $\mathrm{TiO}_{2}$ for the destruction of target compounds, were discussed. The nanostructured catalysts efficiently degrade toxic compounds released by cyanobacteria blooms and EDCs in water. NOx and VOCs in air are efficiently removed by photocatalysis under UV or visible irradiation. For photocatalytic disinfection, semiconductor photocatalysts effectively enhances SODIS at the pilot scale and under natural sunlight conditions. In addition, the nanocrystalline titania materials are excellent candidates to develop efficient DSCs for direct solar energy conversion to electricity. The enhancement of the selectivity of $\mathrm{TiO}_{2}$ photocatalysis through nanoscale modification and functionalization of $\mathrm{TiO}_{2}$ photocatalysts was also described. An engineered $\mathrm{TiO}_{2}$ photocatalyst with controlled properties through innovative material design and processing can serve as an excellent green material for the selective destruction of target contaminants in water. Finally, the formation and roles of ROS during the semiconductor photocatalysis were discussed. The production and role of the different ROS are dependent on the photocatalyst, reaction conditions and target compounds. It is critical to accurately determine the production of ROS and understand their interaction during specific semiconductor photocatalysis for practical water treatment applications. 


\section{Acknowledgments}

All authors contributed equally to this work.

D. D. Dionysiou, S. C. Pillai, J. A. Byrne, P. S. M. Dunlop, and K. O'Shea wish to acknowledge financial support under the US-Ireland R\&D Partnership Initiative from the Department of Employment and Learning Northern Ireland (DELNI), the Science Foundation Ireland (SFI-grant number 10/US/I1822) and the US National Science Foundation-CBET (Award 1033317). D. D. Dionysiou would like to acknowledge the Cyprus Research Promotion Foundation through Desmi 20092010 which was co-funded by the Republic of Cyprus and the European Regional Development Fund of the EU under contract number NEA IPODOMI/STRATH/ 0308/09. P. Falaras acknowledges funding by the European Community's Seventh Framework Programme (FP7/2007-2013) under grant agreement of the CLEAN WATER $\left(n^{\circ} 227017\right)$ and SANS $\left(n^{\circ} 246124\right)$ projects.

\section{References}

1. Vilar, V. J. P.; Gomes, A. I. E.; Ramos, V. M.; Maldonado, M. I.; Boaventur, R. A. R. Photochem. Photobiol. Sci. 2009, 8, 691-698.

2. Pichat, P. Appl. Catal., B 2010, 99, 428-434.

3. Higarashi, M. M.; Jardim, W. F. Catal. Today 2002, 76, 201-207.

4. Fujishima, A.; Honda, K. Nature 1972, 238, 37-38.

5. Zoua, L.; Luo, Y.; Hooper, M.; Hu, E. Chem. Eng. Process. 2006, 45, 959-964.

6. Dalton, J. S.; Janes, P. A.; Jones, N. G.; Nicholson, J. A.; Hallam, K. R.; Allen, G. C. Environ. Pollut. 2002, 120, 415-422.

7. Konstantinou, I. K.; Albanis, T. A. Appl. Catal., B 2004, 49, 1-14.

8. Hajkova, P.; Spatenka, P.; Horsky, J.; Horska, I.; Kolouch, A. Plasma Process. Polym. 2007, 4, S397-S401.

9. Jardim, W. F.; Moraes, S. G.; Takiyama, M. M. K. Water Res. 1997, 31, $1728-1732$.

10. Dimitrov, D. Colloids Surf., A 2006, 282-283, 8-10.

11. Dastjeridi, R.; Montazer, M. A. Colloids Surf., B 2010, 79, 5-18.

12. Xu, P.; Zeng, G. M.; Huang, D. L.; Feng, C. L.; Hu, S.; Zhao, M. H.; Lai, C.; Wei, Z.; Huang, C.; Xie, G. X.; Liu, Z. F. Sci. Total Environ. 2012, 424, $1-10$.

13. Comenares, J. C.; Luque, R.; Campelo, J. M.; Colmenares, F.; Karpiński, Z.; Romero, A. A. Materials 2009, 2, 2228-2258.

14. Bao, N.; Shen, L.; Takata, T.; Domen, K. Chem. Mater. 2008, 20, 110-117.

15. Hu, J.-S.; Ren, L.-L.; Guo, Y.-G.; Liang, H.-P.; Cao, A.-M.; Wan, L.-J.; Bai, C.-L. Angew. Chem., Int. Ed. 2005, 44, 1269-1273.

16. Gonzalez-Oliver, C.; Jamesl, P.; Rawson, H. J. Non-Cryst. Solids. 1982, 48, $129-152$.

17. Sladek, K. Ind. Eng. Chem. Prod. Res. Dev. 1972, 11, 92-96.

18. Mooney, J.; Radding, S. Annu. Rev. Mater. Sci. 1982, 12, 81-101.

19. Kuznetzon, V. J. Cryst. Growth 1968, 3-4 (C), 405-410. 
20. Lindh, A. Lithos 1972, 4, 325-343.

21. Choy, K. Prog. Mater. Sci. 2003, 48, 57-170.

22. Marcilly, C.; Courty, P.; Delmon, B. J. Am. Ceram. Soc., 53, 56-57.

23. Li, D.; Haneda, H.; Hishita, S.; Ohashi, N. Chem. Mater. 2005, 17, 2588-2595.

24. Feng, S.; Xu, R. Acc. Chem. Res. 2001, 34, 239-247.

25. Hench, L.; West, J. Chem. Rev. 1990, 90, 33-72.

26. Umebayashi, T.; Yamaki, T.; Itoh, H.; Asai, K. Appl. Phy. Lett. 2002, 81, 454-456.

27. Fujishima, A.; Rao, T.; Tryk, D. J. Photochem. Photobiol., C 2000, 1, 1-21.

28. O'Regan, B.; Gratzel, M. Nature 1991, 353, 737-740.

29. Kresge, C.; Leonowicz, M.; Roth, W.; Vartuli, J.; Beck, J. Nature 1992, 359, 710-712.

30. Pelaez, M.; de la Cruz, A.; Elias, S.; Polycarpos, F.; Dionysiou, D. Catal. Today 2009, 144, 19-25.

31. Han, C.; Pelaez, M.; Likodimos, V.; Kontos, A.; Falaras, P.; O'Shea, K.; Dionysiou, D. Appl. Catal., B 2011, 107, 77-87.

32. Barnes, P.; Randeniya, L.; Murphy, A.; Gwan, P; Plumb, I.; Glasscock, J.; Grey, I.; Li, C. Dev. Chem. Eng. Miner. Process. 2006, 14, 51-70.

33. Eder, D.; Motta, M.; Windle, A. Nanotechnology 2009, 20, 055602.

34. Dvoranova, D.; Brezova, V.; Mazur, M.; Malati, M. Appl. Catal., B 2002, $37,91-105$.

35. Xu, a.; Gao, Y.; Liu, H. J. Catal. 2002, 207, 151-157.

36. Hurum, D.; Agrios, A.; Gray, K. J. Phys. Chem. B 2003, 107, 4545-4549.

37. Chen, X.; Nao, S. Chem. Rev. 2007, 107, 2891-2595.

38. Eiden-Assmann, S.; Widoniak, J.; Maret, G. Chem. Mater. 2004, 6-11.

39. Han, C.; Luque, R.; Dionysiou, D. Chem. Commun. 2012, 48, 1860-1862.

40. Srisitthiratkul, C.; Pongsorrarith, V.; Instasanta, N. Appl. Surf. Sci., 257, 8850-8856.

41. Dokou, E.; Farneth, W.; Barteau, M. Stud. Surf. Sci. Catal. 2000, 130, $3167-3172$.

42. Tan, J.; Fernandez, Y.; Liu, D.; Maroto-Valer, M.; Bian, J.; Zhang, X. Chem. Phys. Lett. 2012, 531, 149-154.

43. Kang, Q.; Yang, L.; Cai, Q. Bioelectrochemistry 2008, 74, 62-65.

44. Ma, C.; Zhou, Z.; Wei, H.; Yang, Z.; Wang, Z.; Zhang, Y. Nanoscale Res. Lett. 2011, 6, 536.

45. Ge, L.; Zuo, F.; Liu, J.; Ma, Q.; Wang, C.; Xun, D.; Bartels, L.; Feng, P. J. Phys. Chem. C 2102, 116, 13708-13714.

46. Tsuji, I.; Kato, H.; Kobayashi, H.; Hudo, A. J. Am. Chem. Soc. 2004, 126, 13406-13413.

47. Zhang, Q. F.; Chou, T. P.; Russo, B.; Jenekhe, S. A.; Cao, G. Z. Adv. Funct. Mater. 2008, 18, 1654-1660.

48. Umar, A.; Rahman, M. M.; Hahn, Y. B. Talanta 2009, 78, 284-289.

49. Bao, J.; Zimmler, M. A.; Capasso, F. Nano Lett. 2006, 6, 1719-1722.

50. Aghababazadeh, R.; Mazinani, B.; Mirhabibi, A.; Tamizifar, M. J. Phys.: Conf. Ser. 2006, 26, 312-314. 
51. Ao, W.; Li, J.; Yang, H.; Zeng, X.; Ma, X. Powder Technol. 2006, 168, 148-151.

52. Shen, L.; Bao, N.; Yanagisawa, K.; Domen, K.; Gupta, A.; Grimes, C. A. Nanotechnology 2006, 17, 5117-5123.

53. Lu, H. B.; Li, H.; Liao, L.; Tian, Y.; Shuai, M.; Li, J. C.; Hu, M. F.; Fu, Q.; Zhu, B. P. Nanotechnology 2008, 19, 045604, 7pp.

54. Chu, D.; Masuda, Y.; Ohji, T.; Kato, K. Langmuir 2010, 26, 2811-2815.

55. Chung, Y.-A.; Chang, Y.-C.; Lu, M.-Y.; Wang, C.-Y.; Chen, L.-J. J. Electrochem. Soc. 2009, 156, F75-F79.

56. Zhai, T.; Xie, S.; Zhao, Y.; Sun, X.; Lu, X.; Yu, M.; Xu, M.; Xiao, F.; Tong, Y. CrystEngComm. 2012, 14, 1850-1855.

57. Xu, P.; Zeng, G. M.; Huang, D. L.; Feng, C. L.; Hu, S.; Zhao, M. H.; Lai, C.; Wei, Z.; Huang, C.; Xie, G. X.; Liu, Z. F. Sci. Total Environ. 2012, 424, $1-10$.

58. Liu, S.-Q. Environ. Chem. Lett. 2012, 10, 209-216.

59. Kato, R.; Komatsu, T. J. Inorg. Organomet. Polym. 2012, 22, DOI:10.1007/ s10904-012-9725-5.

60. Zhou, X.; Yang, H.; Wang, C.; Mao, X.; Wang, Y.; Yang, Y.; Liu, G. J. Phys. Chem. C 2010, 114, 17051-17061.

61. Chowdhury, P. S.; Arya, P. R.; Raha, K. Synth. React. Inorg. Met. 2007, 37, 447-451.

62. Ipe, B. I.; Lehnig, M.; Niemeyer, C. M. Small 2005, 1, 706-709.

63. Yang, F.; Yan, N.-N.; Huang, S.; Sun, Q.; Zhang, L.-Z.; Yu, Y. J. Phys. Chem. C 2102, 116, 9078-9084.

64. Ren, G.; Lin, Z.; Gilbert, B.; Zhang, J.; Huang, F.; Liang, J. Chem. Mater. 2008, 20, 2438-2443.

65. Komarneni, S.; Menon, V. C.; Li, Q. H Ceram. Trans. 1996, 62, 1042-1122.

66. Periyat, P.; Leyland, N. 1.; McCormack, D. E.; Colreavy, J.; Corr, D.; Pillai, S. C J. Mater. Chem. 2010, 20, 3650-3655.

67. Komarneni, S.; Rajha, R. K; Katsuki, H. Mater. Chem. Phys. 1999, 60, $50-54$.

68. Wilson, G. J.; Will, G. D.; Frost, R. L.; Montgomery, S. A. J. Mater. Chem. 2002, 12, 1787-1791.

69. Wang, H.; Xu, J. Z.; Zhu, J. J.; Chen, H. Y. J. Cryst. Growth 2002, 244, 88-94.

70. Liao, X. H.; Chen, N. Y.; Xu, S.; Yang, S. B.; Zhu, J. J. J. Cryst. Growth 2003, 252, 593-59.

71. Zheng, Y.; Lv, K.; Wang, Z.; Deng, K.; Li, M. J. Mol. Catal. A: Chem. 2012, 356, 137-143.

72. Suprabha, T.; Roy, H. G.; Thomas, J.; Kumar, K. P.; Mathew, S. Nanoscale Res. Lett. 2009, 4, 144-152.

73. Siddiquey, I. A.; Furusawa, T.; Sato, M.; Suzuki, M. Mater. Res. Bull. 2008, 43, 3416-3424.

74. Biddlecombe, G. B.; Gun'ko, Y. K.; Kelly, J. M.; Pillai, S. C.; Coey, J. M. D.; Venkatesan, M.; Douvalis, A. P. J. Mater. Chem. 2011, 11, 2937-2939.

75. Gun'ko, Y. K.; Pillai, S. C.; McInerney, D. J. Mater. Sci.: Mater. Electro. 2001, 12, 299-302. 
76. Shafi, K. V. P. M.; Ulman, A.; Yan, X.; Yang, N. L.; Estourne‘s, C.; White, H.; Rafailovich, M. Langmuir 2001, 17, 5093-5097.

77. Geng, J.; Lv, Y.; Lu, D. J.; Zhu, J. J. Nanotechnology 2006, 17, 2614-2620.

78. Pan, H. C.; Liang, F. P.; Mao, C. J.; Zhu, J. J. Nanotechnology 2007, 18, 195606, 6pp.

79. Xu, L.; Jiang, L. P.; Zhu, J. J. Nanotechnology 2009, 20, 045605, 6pp.

80. Xu, K.; Mao, C. J.; Geng, J.; Zhu, J. J. Nanotechnology 2007, 18, 315604, 5 pp.

81. Khanjani, S.; Morsali, A.; Joo, S. W. Ultrason. Sonochem. 2013, 20, 734-739.

82. Bhatte, K. D.; Sawant, D. N.; Pinjari, D. V.; Pandit, A. B.; Bhanage, B. M. Mater. Lett. 2012, 77, 93-95.

83. Guo, W.; Lin, Z.; Wang, X.; Song, G. Microelectron. Eng. 2003, 66, 95-101.

84. Definition of a Nanomaterial. European Commission. http://ec.europa.eu/ environment/chemicals/nanotech/index.htm\#definition.

85. Editorial. Nat. Nanotechnol. 2007, 2, 257.

86. Litter, M. I.; Choi, W.; Dionysiou, D. D.; Falaras, P.; Hiskia, A.; Li Puma, G.; Pradeep, T.; Zhao, J. J. Hazard. Mater. 2012, 211-12, 1-2, Editorial.

87. Likodimos, V.; Dionysiou, D. D.; Falaras, P. Rev. Environ. Sci. Biotechnol. 2010, 9, 87-94.

88. Pastrana-Martinez, L. M.; Faria, J. L.; Dona-Rodriguez, J. M.; FernandezRodriguez, C.; Silva, A. M. T. Appl. Catal., B 2012, 113-114, 221-227.

89. Liu, G.; Han, C.; Pelaez, M.; Zhu, D.; Liao, S.; Likodimos, V.; Ioannidis, N.; Kontos, A. G.; Falaras, P.; Dunlop, P. S. M.; Byrne, J. A.; Dionysiou, D. D. Nanotechnology 2012, 23, 294003, 10pp.

90. Pastrana-Martínez, L. M.; Morales-Torres, S.; Likodimos, V.; Figueiredo, J. L.; Faria, J. L.; Falaras, P.; Silva, A. M. T. Appl. Catal., B 2012, 123- 124, 241-256.

91. Pelaez, M.; Falaras, P.; Likodimos, V.; Kontos, A. G.; de la Cruz, A. A.; O'Shea, K.; Dionysiou, D. D. Appl. Catal., B 2010, 99, 378-387.

92. Moustakas, N. G.; Kontos, A. G.; Likodimos, V.; Katsaros, F.; Boukos, N.; Tsoutsou, D.; Dimoulas, A.; Romanos, G. E.; Dionysiou, D. D.; Falaras, P. Appl. Catal., B 2013, 130-131, 14-24.

93. Triantis, T. M.; Fotiou, T.; Kaloudis, T.; Kontos, A. G.; Falaras, P.; Dionysiou, D. D.; Pelaez, M.; Hiskia, A. J. Hazard. Mater. 2012, 211, 196-202.

94. Mboula, V. M.; Hequet, V.; Gru, Y.; Colin, R.; Andres, Y. J. Hazard. Mater. 2012, 209, 355-364.

95. Papageorgiou, S. K.; Katsaros, F. K.; Favvas, E. P.; Romanos, G.; Athanasekou, C. P.; Beltsios, K. G.; Tzialla, O. I.; Falaras, P. Water Res. 2012, 46, 1858-1872.

96. Romanos, G. E.; Athanasekou, C. P.; Katsaros, F. K.; Kanellopoulos, N. K.; Dionysiou, D. D.; Likodimos, V.; Falaras, P. J. Hazard. Mater. 2012, 211-212, 304-316.

97. Athanasekou, C. P.; Romanos, G. E.; Katsaros, F. K.; Kordatos, K.; Likodimos, V.; Falaras, P. J. Membr. Sci. 2012, 392-393, 192-203. 
98. Han, C.; Doepke, A.; Cho, W.; Likodimos, V.; de la Cruz, A. A.; Back, T.; Heineman, W. R.; Halsall, H. B.; Shanov, V. N.; Schulz, M. J.; Falaras, P.; Dionysiou, D. D. Adv. Func. Mater. 2012, DOI: 10.1002/adfm.201201920.

99. Kontos, A. I.; Kontos, A. G.; Tsoukleris, D. S.; Vlachos, G. D.; Falaras, P. Thin Solid Films 2007, 515, 7370-7375.

100. Chorianopoulos, N. G.; Tsoukleris, D. S.; Panagou, E. Z.; Falaras, P.; Nychas, G.-J. E. Food Microbiol. 2011, 28, 164-170.

101. Kontos, A. G.; Katsanaki, A.; Likodimos, V.; Maggos, T.; Kim, D.; Vasilakos, C.; Dionysiou, D. D.; Schmuki, P.; Falaras, P. Chem. Eng. J. 2012, 179, 151-157.

102. Pelaez, M.; Nolan, N. T.; Pillai, S. C.; Seery, M. K.; Falaras, P.; Kontos, A. G.; Dunlop, P. S. M.; Hamilton, J. W. J.; Byrne, J. A.; O’Shea, K.; Entezari, M. H.; Dionysiou, D. D. Appl. Catal.. B 2012, 125, 331-349.

103. Wang, T. C.; Lu, N.; Li, J.; Wu, Y. Environ. Sci. Technol. 2011, 45, 9301-9307.

104. Davezza, M.; Fabbri, D.; Prevot, A. B.; Pramauro, E. Environ. Sci. Pollut. Res. 2011, 18, 783-789.

105. Editorial. Nat. Nanotechnol. 2007, 2, 325.

106. O’Regan; Grätzel, M. Nature 1991, 353, 737.

107. Hagfeldt, A.; Grätzel, M. Chem. Rev. 1995, 95, 49-68.

108. Hagfeldt, A.; Boschloo, G.; Sun, L.; Kloo, L.; Pettersson, H. Chem. Rev. 2010, $110,6595$.

109. Green, M. A.; Emery, K.; Hishikawa, Y.; Warta, W.; Dunlop, E. D. Prog. Photovoltaics 2011, 19, 565-572.

110. Vougioukalakis, G. C.; Philippopoulos, A. I.; Stergiopoulos, T.; Falaras, P. Coord. Chem. Rev. 2011, 255, 2602-2621.

111. Stergiopoulos, T.; Kontos, A.; Likodimos, V.; Perganti, D.; Falaras, P. J. Phys. Chem. C 2011, 115, 10236-10244.

112. Stergiopoulos, T.; Rozi, E.; Hahn, R.; Schmuki, P.; Falaras, P. Adv. Energy Mater. 2011, 1, 569-572.

113. Progress on Sanitation and Drinking Water: 2012 Update; World Health Organization, UNICEF: Geneva, Switzerland, 2012.

114. Clasen, T.; Edmondson, P. Int. J. Hyg. Environ. Health 2006, 209, 173-181.

115. Economic and Health Effects of Increasing Coverage of Low Cost Household Drinking Water Supply and Sanitation Interventions to Countries Off-Track To Meet MDG Target 10; World Health Organization: Geneva, Switzerland, 2007.

116. Burch, J. D.; Thomas, K. E. Sol. Energy 1998, 64, 87-97.

117. Clasen, T. F.; Haller, L. Water Quality Interventions To Prevent Diarrhoea: Cost and Cost-Effectiveness; World Health Organization: Geneva, Switzerland, 2008.

118. Matsunaga, T.; Tomoda, R.; Nakajima, T.; Wake, H. FEMS Microbiol. Lett. 1985, 29, 211-214.

119. Blake, D. M.; Maness, P. C.; Huang, Z.; Wolfrum, E. J.; Huang, J.; Jacoby, W. A. Sep. Purif. Method. 1999, 28, 1-50.

120. McCullagh, C; Robertson, J. M.; Bahnemann, D. W.; Robertson, P. J. K. Res. Chem. Intermed. 2007, 33, 359-375. 
121. Malato, S.; Fernandez-Ibanez, P.; Maldonado, M. I.; Blanco, J.; Gernjak, W. Catal. Today 2009, 147, 1-59.

122. Dalrymple, O. K.; Stefanakos, E.; Trotz, M. A.; Goswami, D. Y. Appl. Catal., B 2010, 98, 27-38.

123. Cho, M.; Chung, H.; Choi, W.; Yoon, J. Water Res. 2004, 38, 1069-1077.

124. Rincon, A. G.; Pulgarin, C.; Adler, N.; Peringer, P. J. Photochem. Photobiol., A 2001, 139, 233-241.

125. Huang, Z.; Maness, P.; Blake, D. M.; Wolfrum, E. J.; Smolinski, S. L.; Jacoby, W. A. J. Photochem. Photobiol., A 2000, 130, 163-170.

126. Wainwright, M. Int. J. Antimicrob. Agents 2000, 16, 381-394.

127. Sunada, K.; Watanabe, T.; Hashimoto, K. J. Photochem. Photobiol., A 2003, 156, 227-233.

128. Rincon, A.; Pulgarin, C. Sol. Energy 2004, 77, 635-648.

129. Byrne, J. A.; Eggins, B. R.; Brown, N. M. D.; McKinney, B.; Rouse, M. Appl. Catal., B 1998, 17, 25-36.

130. McMurray, T. A.; Byrne, J. A.; Dunlop, P. S. M.; Winkelman, J. G. M.; Eggins, B. R.; McAdams, E. T. Appl. Catal,. A 2004, 262, 105-110.

131. Alrousan, D. M. A.; Dunlop, P. S. M.; McMurray, T. A.; Byrne, J. A. Water Res. 2009, 43, 47-54.

132. Dunlop, P. S. M.; Byrne, J. A.; Manga, N.; Eggins, B. R. J. Photochem. Photobiol., A 2002, 148, 355-363.

133. Dunlop, P. S. M.; McMurray, T. A.; Hamilton, J. W. J.; Byrne, J. A. J. Photochem. Photobiol., A 2008, 196, 113-119.

134. Sunnotel, O.; Verdoold, R.; Dunlop, P. S. M.; Snelling, W. J.; Lowery, C. J.; Dooley, J. S. G.; Moore, J. E.; Byrne, J. A. J. Water Health 2010, 8, 83-91.

135. Alrousan, D. M. A.; Polo-López, M. I.; Dunlop, P. S. M.; FernándezIbáñez, P.; Byrne, J. A. Appl. Catal., B 2012, 128, 126-134.

136. Rengifo-Herrera, J. A.; Pulgarin, C. Sol. Energy 2010, 84, 37-43.

137. Matthews, R. W. Water Res. 1986, 20, 569-578.

138. Paz, Y. C. R. Chim. 2006, 9, 774-787.

139. Choi, H.; Kim, Y.; Varma, R. S.; Dionysiou, D. D. Chem. Mater. 2006, 18, 5377-5384.

140. Doll, T. E.; Frimmel, F. H. Water Res. 2005, 39, 403-411.

141. Yu, J. G.; Yu, J. C.; Leung, M. K. P.; Ho, W. K.; Cheng, B.; Zhao, X. J.; Zhao, J. C. J. Catal. 2003, 217, 69-78.

142. Shiraishi, Y.; Saito, N.; Hirai, T. J. Am. Chem. Soc. 2005, 127, 12820-12822.

143. Morishita, M.; Shiraishi, Y.; Hirai, T. J. Phys. Chem. B 2006, 110, 17898-17905.

144. Ghosh-Mukerji, S.; Haick, H.; Paz, Y. J. Photochem. Photobiol., A 2003, 160, 77-85.

145. Sharabi, D.; Paz, Y. Appl. Catal., B 2010, 95, 169-178.

146. Paz, Y. Solid State Phenom. 2010, 162, 135-162.

147. Nussbaum, M.; Paz, Y. Phys. Chem. Chem. Phys. 2012, 14, 3392-3399.

148. Matos, J.; Laine, J.; Herrmann, J. M. Appl. Catal., B 1998, 18, 281-291.

149. Inumaru, K.; Murashima, M.; Kasahara, T.; Yamanaka, S. Appl. Catal., B 2004, 52, 275-280. 
150. Ghosh-Mukerji, S.; Haick, H.; Schvartzman, M.; Paz, Y. J. Am. Chem. Soc. 2001, 123, 10776-10777.

151. Ramstörm, O.; Ansell, R. J. Chirality 1998, 10, 195-209.

152. Yoneyama, H.; Haga, S.; Yamanaka, S. J. Phys. Chem. 1989, 93, 4833-4837.

153. Shimizu, K. I.; Kaneko, T.; Fujishima, T.; Kodama, T.; Yoshida, H.; Kitayama, Y. Appl. Catal., A 2002, 225, 185-195.

154. Aronson, B. J.; Blanford, C. F.; Stein, A. Chem. Mater. 1997, 9, 2842-2851.

155. Kato, R.; Shimura, N.; Ogawa, M. Chem. Lett. 2008, 37, 76-77.

156. Choi, H.; Antoniou, M. G.; Pelaez, M.; de la Cruz, A. A.; Shoemaker, J. A.; Dionysiou, D. D. Environ. Sci. Technol. 2007, 41 (21), 7530-7535.

157. Choi, W. Catal. Surv. Asia 2006, 10 (1), 16-28.

158. Serpone, N; Emeline, A. V. J. Phys. Chem. Lett. 2012, 3, 673-677.

159. Kim, D. K.; O’Shea, K. E.; Cooper, W. J. Ultrason. Sonochem. 2012, 19, 959-968.

160. Linsebigler, A. L.; Lu, G.; Yates, J. T. Chem. Rev. 1995, 95, 735-758.

161. Sun, J.; Qiao, L.; Sun, S.; Wang, G. J. Hazard. Mater. 2008, 155, 312-319.

162. O’Shea, K. E.; Dionysiou, D. D. J. Phys. Chem. Lett. 2012, 3 (15), 2112-2113.

163. Cooper, W. J.; Cramer, C. J.; Martin, N. H.; Mezyk, S. P.; O’Shea, K. E.; von Sonntag, C. Chem. Rev. 2009, 109 (3), 1302-1345.

164. Buxton, G. V.; Greenstock, C. L.; Helman, W. P.; Ross, A. B. J. Phys. Chem. Ref. Data 1988, 17, 513-886.

165. Li, W.; Li, D.; Lin, Y.; Wang, P.; Chen, W.; Fu, X.; Shao, Y. J. Phys. Chem. C 2012, 116, 3552-3560.

166. Song, W.; Xu, T.; Cooper, W. J.; Dionysiou, D. D.; de la Cruz, A, A.; O’Shea, K. E. Envrion. Sci. Technol. 2009, 43 (5), 1487-1492.

167. Schwarz, P. F.; Turro, N. J.; Bossmann, S. H.; Braun, A. M.; Wahab, A. A. A.; Dür, H. J. Phys. Chem. B 1997, 101, 7127-7134.

168. Fu, H.; Zhang, L.; Zhang, S.; Zhu, Y. J. Phys. Chem. B 2006, 110 (7), 3061-3065.

169. Louit, G.; Foley, S.; Cabillic, J.; Coffigny, H.; Taran, F.; Valleix, A.; Renault, J. P.; Pin, S. Radiat. Phys. Chem. 2005, 72, 119-124.

170. Ishibashi, K.; Fujishima, A.; Watanabe, T.; Hashimoto, K. J. Photochem. Photobiol., A. 2000, 134, 139-142.

171. Nosaka, Y.; Daimon, T.; Nosaka, A. Y.; Murakami, Y. Phys. Chem. Chem. Phys. 2004, 6, 2917-2918.

172. Haag, W. R.; Hoigne, J. Envrion. Sci. Technol. 1986, 20, 341-348.

173. Konaka, R.; Kasahara, E.; Dunlap, W. C.; Yamamoto, Y.; Chien, K. C.; Inoue, M. Free Radical Biol. Med. 1999, 27, 294-300.

174. Miller, W. L.; Kester, D. R. Anal. Chem. 1988, 60 (24), 2711-2715.

175. Diaz-Uribe, C. E.; Daza, M. C.; Martínez, F.; Páez-Mozo, E. A.; Guedes, C. L. B.; Mauro, E. D. J. Photochem. Photobiol., A. 2010, 215, 172-178.

176. Hirakawa, T.; Nakaoka, Y.; Nishino, J.; Nosaka, Y. J. Phys. Chem. B. 1999, 103, 4399-4403.

177. Auffan, M.; Pedeutour, M.; Rose, J.; Masion, A.; Ziarelli, F.; Borschneck, D.; Chaneac, C.; Botta, C.; Chaurand, P.; Labille, J.; Bottero, J. Environ. Sci. Technol. 2010, 44, 2689-2694. 